\title{
Gamification-less: may gamification really foster civic participation? A controlled field experiment
}

\author{
Marco Romano $^{1}$ (D) Paloma Díaz ${ }^{2}$ (D) Ignacio Aedo ${ }^{2}$ (D
}

Received: 24 June 2020 / Accepted: 3 June 2021 / Published online: 14 June 2021

(c) The Author(s) 2021

\begin{abstract}
In the context of smart communities, it is essential an active and continuous collaboration between citizens, organizations and institutions. There are several cases where citizens may be asked to participate such as in public decision-making process by informing, voting or proposing projects or in crisis management by sharing precise and timely information with other citizens and emergency organizations. However, these opportunities do not automatically result in participatory practices sustained over time. Mobile technologies and social networks provide the substratum for supporting formal empowerment, but citizen engagement in participation processes is still an open issue. One of the techniques used to improve engagement is gamification based on the humans' predisposition to games. So far, we still lack studies that can prove the advantage of gamified systems respect to non-gamified ones in civic participation context. In this work, we present a between-group design experiment performed in the wild using two mobile applications enabling civic participation, one gamified and the other not. Our results highlight that the gamified application generates a better user experience and civic engagement.
\end{abstract}

Keywords Civic engagement $\cdot$ Gamification $\cdot$ Pervasive applications $\cdot$ Social sensing $\cdot$ HCI study

\section{Introduction}

Civic participation is an important factor for the progress of a community (Jennings 2004). Magnette (2003) points out that civic participation is perceived as an essential component of any level of "governance". In fact, in many cities, residents can vote or propose projects for the community, give opinions or feedback about the government's actions, etc. Within this context, researchers, local governments and companies have demonstrated a growing interest in studying, developing and adopting technologies and techniques to foster civic participation. This is especially true within the context of Smart Communities (Coe et al. 2001). The most

Marco Romano

marromano@unisa.it

Paloma Díaz

pdp@inf.uc3m.es

Ignacio Aedo

aedo@ia.uc3m.es

1 Department of Computer Science, University of Salerno, Fisciano, Italy

2 Department of Computer Science, University of Carlos III de Madrid, Leganés, Spain famous definition of Smart Community is given by the California Institute for Smart Communities (Wilson 1997) that defines a "Smart" Community as "a community in which government, business, and residents understand the potential of information technology, and make a conscious decision to use that technology to transform life and work in their region in significant and positive ways.". In general, smart communities focus on social capital and request an active and continuous collaboration between citizens, private organizations and institutions (Coe et al. 2001; Wilson 1997). Nevertheless, participation cannot be taken for granted, it needs to be fostered. Indeed, Delli Carpini (2000) state that citizens become engaged when they are motivated and have both the abilities and the opportunities to participate through the right means, while the authors in (Makri et al. 2020) highlight that motivation can depend on various social, economic and cultural statuses, stressing the need to explore motivational methodologies.

In smart communities, social networks and mobile applications are often exploited to involve and integrate citizens into decision-making (Coe et al. 2001; Mainka et al. 2016; Romano et al. 2016b). From a technical point of view, social networks are difficult to integrate into a decision-making process due to the quantity and quality of the information 
generated. Indeed, as posited in (Díaz et al. 2017), mixed platforms combining both spontaneously generated information through social networks and curated data collected through mobile applications might be a good compromise. This is the case of Comuni-Chiamo, ${ }^{1}$ a mobile app that allows citizens to send photos of malfunctions to the local agreed-upon government or the My112 mobile app $^{2}$ that allows people to send notifications enriched with photos to allow an emergency operator to immediately evaluate the situation.

Anyway, as Hassan states in (2017), such platforms usually have low engagement levels not achieving the purpose for which they were created. One of the strategies recently explored to improve engagement in activities that are not extrinsically rewarding is to apply gamification (Pelling, 2011). Gamification is commonly defined as the use of game elements in non-game contexts (Deterding et al. 2011) in order to make a system use more attractive by taking profit from the intrinsically rewarding features of games. Gamification looks to be suitable to promote the participation and the relationship between citizens and the organizations (Coronado Escobar and Urriago 2014) though it has to be carefully adopted. As pointed out in (Thiel 2016) gamification does not work in all domains, and some elements might even be harmful towards reaching overall objectives in civic participation.

Gamified applications have been proposed to encourage people to make suggestions to improve the community life (Stembert and Mulder 2013), to improve the communication between city hall public services and people (Rodrigues et al. 2019), to foster young students to care more about sustainability and energy savings (Mylonas et al. 2021) or to be prepared to face crisis situations (Kanat et al. 2013). While such systems suggest that gamification may be applied to foster civic participation, as revealed in (Seaborn and Fels 2015), there is still a lack of data or standards to measure the gamification effects and results that prove the advantage of gamified systems respect to non-gamified ones. A few examples of works aimed at exploring this issue are given by (Stanculescu et al. 2016) (Thom et al. 2012) that explore the benefits on employees' engagement using the enterprise software. In this context, we aim at contributing to ask the question of whether a gamified system fosters civic participation better than a non-gamified one. With that purpose, we present an experiment using two applications for civic participation: one based on game elements introduced in (Romano et al. 2018) and an equivalent version without the game elements. 20 users took part in a between-subjects controlled field experiment for 1 week. The preliminary

\footnotetext{
1 comuni-chiamo.com.

${ }^{2}$ www.madrid.org/112/index.php/actualidad/app-de-emergencia
}

results suggest that gamification may generate a better user experience, leading users to commit themselves to the civic goals of the application. All the gamification elements were positively evaluated by the users and in particular, they appreciated the possibility to interact and compete with other users, and the possibility to progress and access more difficult missions.

The main contributions of the work are the following:

(a) It answers the research question: "May a gamified system foster civic participation better than a non-gamified one?"

(b) It helps to fill the void regarding the lack of knowledge about gamification in civic participation

(c) It identifies which aspects of the user experience and engagement are mostly affected by gamification in this given context

(d) It shows which intrinsic motivators are activated by gamification and how they influence the user behaviour and sentiments

The rest of this paper is structured as follows: Sect. 2 introduces the context of this research. In Sect. 3 we present the gamified application for civic engagement. Section 4 describes the comparison study between the effects on the engagement of the gamified app and the same application after removing the game elements. In Sect. 5 we discuss the results and map them into three intrinsic motivators. In the last section, some conclusions are drawn.

\section{Gamification and civic engagement}

Gamification is commonly referred to as the use of game elements in non-game contexts (Deterding et al. 2011) in order to promote the use of a system by motivating users with the intrinsically rewarding features of games. In (Werbach and Hunter 2011), authors describe how gamification techniques have been used successfully in several contexts, including education (Kapp et al. 2012), medical applications (McCallum 2012), and e-commerce platforms like eBay or Amazon. In all these cases, gamification techniques increased the use of tools by offering a funnier and more enjoyable user experience to such an extent that consumers expect that most of the systems they use present some gamified features (Koivisto and Hamari 2019; Sgueo 2019).

In (Hassan and Hamari 2020), the authors present a literature review on e-participation and state that approaches based on gamification or games can be used to encourage civic participation in the decision-making context. Indeed, the gamification mechanisms can empower the systems used in such a context because they rely on a top-down approach aimed at supporting certain decision-making activities in 
precise sessions, in precise time frames and with precise rules (Hassan and Thibault 2020). An example is given by (Apostolopoulos et al. 2018), in which the authors used gamification to motivate citizens to participate in a cadastral data procedure that includes briefing and data collection. Finally, in (Landers et al. 2018) the authors encourage the use of a gamification approach in democratic-governmental processes to design systems, services and processes that can provide engaging experiences for citizens.

Within this context, game mechanisms are used to improve civic commitment so as to empower citizens' participation in their community in platforms like Community PlanIt ${ }^{3}$ Mysidewalk ${ }^{4}$ and Love Your City! (Stembert and Mulder 2013). Community PlanIt allows citizens to participate in games proposed by the local government for which they earn virtual coins that can be invested to support real projects. Mysidewalk, currently used in Fort Worth in Texas, allows local organizations or governments to send information to people living in a concrete area to get quick feedback and make decisions supported by the interested community. Users are compensated with points that can be utilized to get some little merchandise, for example, water bottles. Love Your City! is an interactive mobile platform aimed at involving neighbors in the co-creation of proposals and ideas to improve their district. Ideas can be spontaneous, or the local authorities can give some explicit opportunities to participate. The system has some features of videogames such as limited time to create and submit a proposal, statistics about time and points.

A different example is given by the Social Credit System that is aimed at fostering good behaviors rather than actions or feedback. It is a pervasive platform supported by the Chinese government still in development and designed to measure and track the level of reliability of citizens and enterprises (Ramadan 2018). The rating is established on the basis of various aspects such as professional conduct, compliance with laws and regulations, etc. The rating is then used to receive rewards. For example, companies with high ratings can more easily access loans and tax reduction. Anyway, in (Ampatzidou et al. 2018) the authors raise an ethical issue warning that gamification can be applied intentionally, or accidentally, as means of coercive governmental practices.

These examples show how game standards can be applied to urban settings. They are essentially used to boost individuals to help, impact and improve public decisions and choices, yet in addition to advance positive practices (Kazhamiakin et al. 2016). Indeed, even the emergency

\footnotetext{
3 communityplanit.org

${ }^{4}$ https://www.madrid.org/112/index.php/actualidad/app-de-emerg encia
}

management process can benefit from such technique since civic participation in emergency decisions and the continuous collaboration among authorities and citizens can help to improve the community resilience and the response efficacy through a service coproduction model (Díaz et al. 2016). Indeed, scientists and companies are studying how game elements may build commitment in emergency preparedness. For example, the use of interactive systems can significantly lower the training costs while game elements can foster civic participation (Kanat et al. 2013). Indeed, citizens could use a web-based game to perform emergency training exercises as described in (Simões et al. 2013).

Evidently, the main reason to use gamification is to rise motivation. Motivation can be divided into intrinsic and extrinsic (Malone 1981). Being intrinsically motivated means to be motivated because of one's believes in the underlying values of something or because one finds it stimulating and enjoyable. Being extrinsically motivated means to expect something in return for what one does such as reward and money. According to the Self-Determination Theory (SDT) (Ryan and Deci, 2000), humans are inherently proactive, with a strong internal desire for growth, and the basic human necessities that promote motivation fall into three categories: Competence, Relatedness, and Autonomy. Competence is related to the ability to learn how to act effectively in the external environment, solving, for example, difficult missions, developing artistic abilities or other competencies. Relatedness is about social connections such as interacting or competing with others. Finally, Autonomy represents the innate need to control one's life and to perform actions in harmony with one's values. Gamification-based systems have to activate these motivators to be engaging. For example, in (Kanat et al. 2013) Competence and Relatedness are softly addressed by letting participants see their progression and compare it with other players. In (Simões et al. 2013) Relatedness is considered by making the game a team effort where each player takes the role of a specific agent in a simulated mission. In (Stembert and Mulder 2013), Autonomy is addressed by allowing users to select only the projects they really pretend to care about, without being compelled.

In the literature, gamification and SDT have been used as a framework for examining students' motivation and engagement in learning. The study presented in (Karra et al. 2019) suggests that STD combined with gamification has positive effects on the motivation of adult students. Indeed, the study showed that intrinsic motivation becomes stronger since game mechanisms refer to human psychological needs and behaviors and students perceive learning with a sense of Autonomy, Competence, and Relatedness.

In (Botte et al. 2020), the authors explore the gamified approach of programming learning software with respect to SDT motivators. During their study, they provided 
interesting considerations regarding the effects of the gamified elements and the SDT. As for Relativeness, they suggest that making students collaborate for a common purpose is more effective than making them compete with each other. As for competence, they claim that testing knowledge in a challenge is a good approach, but the consequences of the challenge should be interesting for the player, otherwise, it risks becoming just a way of getting a badge. Finally, as regards Autonomy, it must be considered that not all users have the same goals, a variety of choices, and leaving the user to decide how to achieve a goal would avoid that they perceive the goals as controlled and in contrast with Autonomy.

Regarding the way to evaluate gamified systems, there is a large variety of mixed methods based on both quantitative and qualitative data in one-off experiments (Toots 2019) (Seaborn and Fels 2015). One of the ways to measure the effects of gamification is by removing gamification features from the system and perform a comparative study as in (Thom et al. 2012), (Stanculescu et al. 2016). Both experiments are concerned with enterprise-oriented software with "traditional" features, like write and share content. Such experiments can help to understand which game elements mostly affect the user experience in a given context, anyway, there is yet little work investigating how and which SDT motivators are activated by the gamification and how they influence the user behavior or sentiments. This lack of knowledge is particularly evident in studies regarding civic participation (Hassan 2017). For such reasons, in this work we, present a study that not only explores the specific benefits of a gamified system on the citizens' experience on respect to a non-gamified one but also map such benefits into the SDT motivators.

In the next section, we describe an application designed considering game elements to activate the intrinsic motivators with the aim to foster civic participation.

\section{The gamified application}

The prototype was already presented in (Romano et al. 2018). It has been designed to involve citizens in collecting information on potential risks that will be analysed by emergency organizations to determine whether a risk notification has to be issued. On the one hand, it has to facilitate the connection between citizens and emergency organizations, improving and enriching their communication through digital content. On the other hand, it has to prepare citizens to identify relevant information that can be used to take such a decision. Additionally, it includes a number of gamification features to foster technology adoption. The idea to use a gamification technique to foster civic participation in the emergency notification field was presented and was initially evaluated through a focus group with potential users in (Romano et al. 2016a). During the activity, the group analysed the proposed gamification mechanisms, the aesthetic aspects of the interface, such as icons and avatars, and the possible material and immaterial rewards. On the basis of the focus group's results, we developed the working prototype presented in (Romano et al. 2018). It was already tested with 11 potential users through a preliminary study performed in a laboratory, with the aim of measuring the first impressions of perceived engagement and identifying usability and technical issues to be improved. The work discussed in the present work introduces the gamified system in the real environment and focuses on the aspects related to the effects gamification causes on citizens' motivation comparing them to the same system without the gamified elements.

Figure 1a shows the home of the application. The application is divided into four main parts: (1) the Control room panel to access available missions (2) the Training room panel to take in courses to improve skills and to be prepared when an emergency occurs; (3) the Ranking panel: to check the achievements obtained by users in the same area; and (4) the Teams panel to manage the teams or to enrol in a new team. Starting from this screen in Fig. 1a users can access to the Control room, the Training room, and the Ranking panels. Missions already accepted by users are accessible through the button with the jet icon, which displays also a counter. Figure $1 \mathrm{~b}$ depicts a mission. The mission status can be open, close or in progress.

Regarding the active training courses, users can use the button with the corner-cap. The last button in the action bar is to access the ranking page. This (see Fig. 2) provides information about users playing in the same city, and some statistics to compare the users' achievements with the rest of the players. Users are engaged by exploiting typical mechanisms of a videogame: they earn points for missions and trainings accomplishing; missions and trainings have a required access level and points are used to level up.

Table 1 presents the main gamified elements included in the application, with the corresponding rationale and SDT intrinsic motivator involved.

\section{Evaluating engagement}

In order to study whether the gamified system might foster civic participation better than a non-gamified one, we designed a between-subjects experiment involving 20 participants. The experiment took place in the wild for one whole week. Participants were asked to participate in missions to prevent emergencies or crises in their area using a mobile app either gamified or not. Figure 3 shows a mission as appears after removing the game elements. 


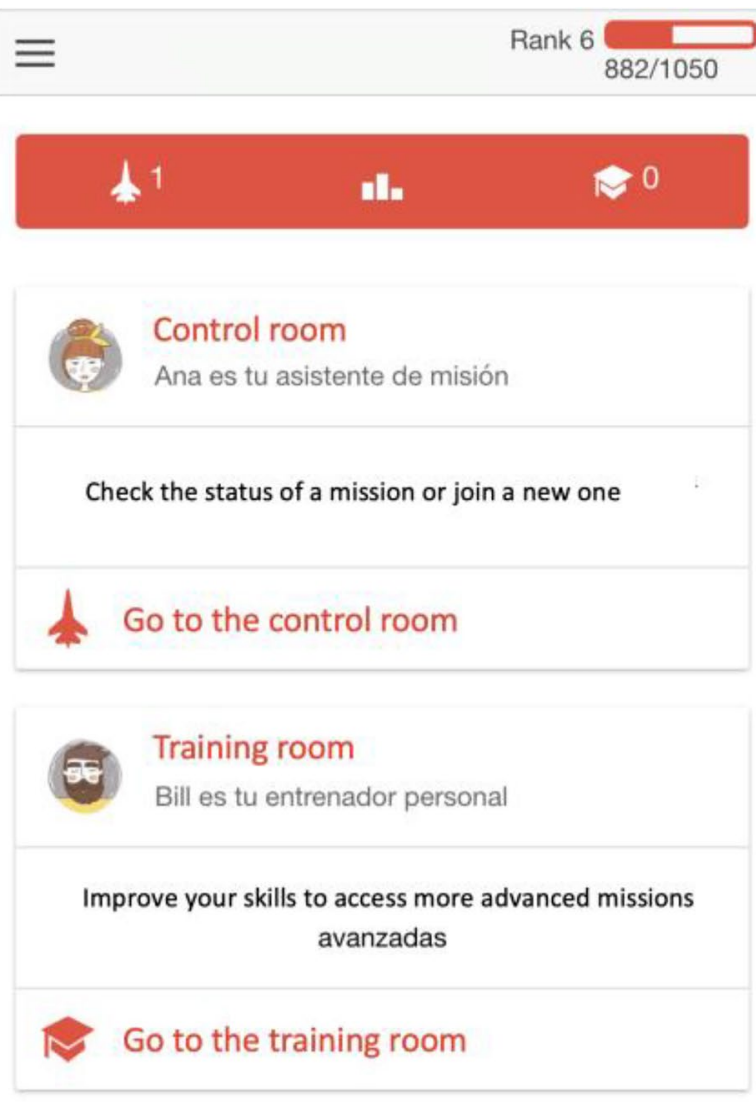

$\mathbf{a}$

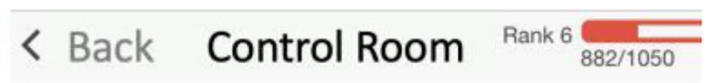

Inspection of urban cleaning in Villaverde..

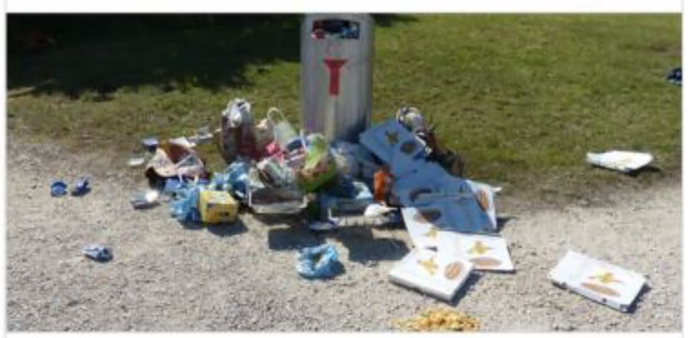

check the cleaning status in the assigned area

State: open

Needed rank: 1

Reward: 10

Location: Leganés/Villaverde

Participants: 0 / 1 required

Accept the mission

b

Fig. 1 a The home screen of the gamified application. b The mission card as it appears in the list of available missions

We collected some system logs to measure the engagement through quantitative data and after the experiment participants were asked to fill out a questionnaire to assess their engagement. During the experiment, we made available the daily missions described in Table 2.

\subsection{Independent and depended variables}

The independent variable in the experiment is the application which the subjects use to perform the experiment, namely the gamified application (GApp) or the application without gamification (NgApp). The dependent variables are the factors impacting the User Engagement that according to O'Brien and Toms's work (2013) are Perceived usability, Felt involvement, Aesthetics, Focused Attention. Besides these 4 factors we also added the following variables from the user logs: number of logins (NoL), number of uploaded pictures (UP) and number of accomplished missions (AM).

\subsection{Between-subjects design}

In our experiment, we decided to adopt a between-subjects design with the aim to limit any bias. 20 Participants were selected randomly and divided into two groups: Gr1 and Gr2. Gr1 will use the gamified app and Gr2 the app without the gamification elements. Additionally, to limit bias due to users' variability, participants were also randomly assigned to each group. Finally, to limit effects linked to an unknown location, the experiment always has taken place in the residence or working area of the subjects.

\subsection{Assessment metrics}

To calculate the perceived engagement of Gr1 and Gr2 we designed a questionnaire (Table 3) based on O'Brien and Toms's work (2013). The questionnaire's items were slightly modified to fit the experiment context.

The questionnaire is divided into 4 scales, namely: Perceived usability, Felt involvement, Aesthetics, and Focused 
Fig. 2 Leaderboard and user's personal statistics

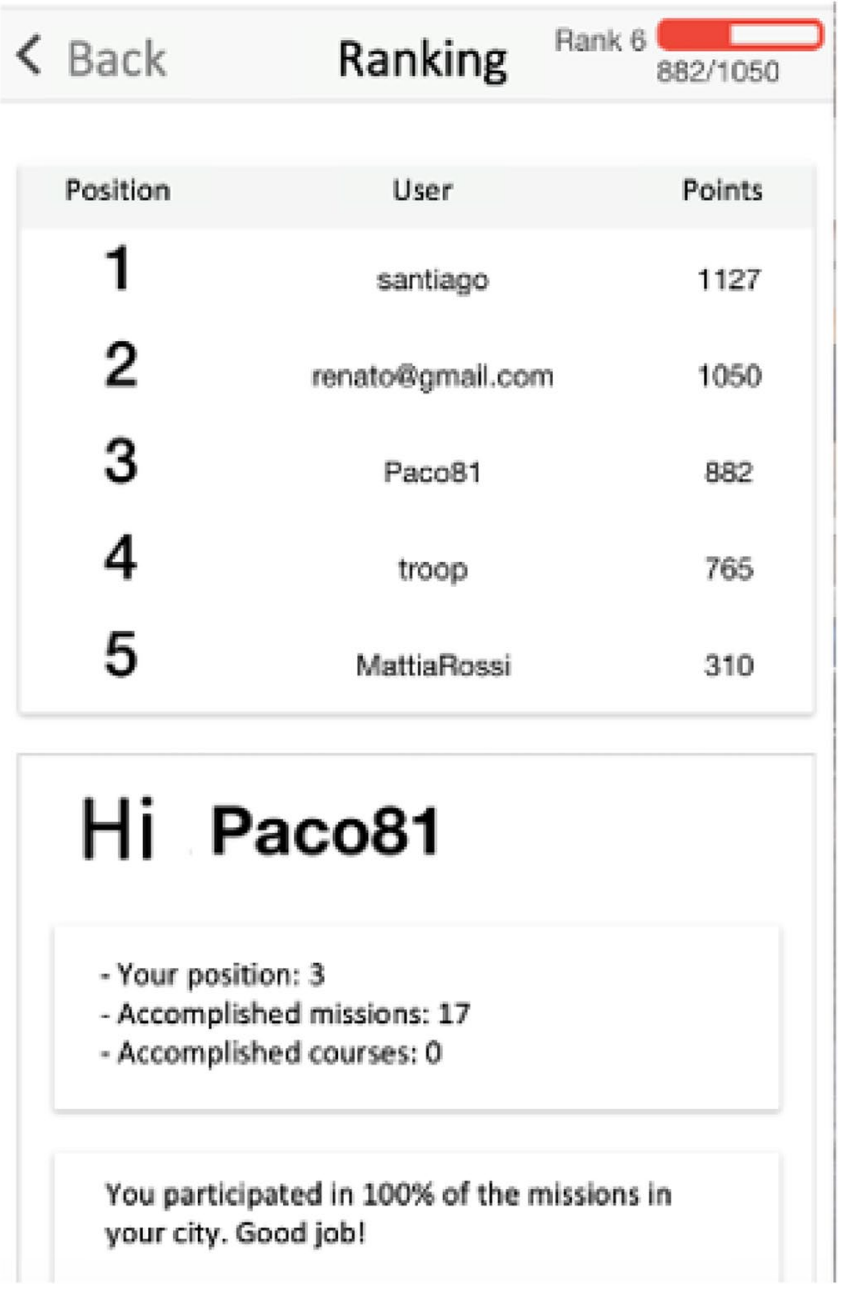

Table 1 Main gamified features of the platform

\begin{tabular}{lll}
\hline Feature & Rationale & Motivator \\
\hline Points and levels & User competences are reflected by means of points and levels & Competence \\
Missions and training courses & Missions and Training courses are designed to activate the Competence & Competence, Autonomy \\
& and the Autonomy. Regarding the Autonomy, users can manage inde- \\
& pendently missions and courses. They can choose on the basis of their \\
& personal preferences and motivations. Regarding the Competence, users \\
& can develop personal skills by getting experience with missions and \\
& learning through the trainings. Progress is reflected by points and levels \\
& that are always visible & \\
Playing in a team and leading a team & to each other and to leak the Relatedness into all the activities available & Relatedness \\
& on the platform & \\
This is to activate the Relatedness by comparing and sharing their pro- & Relatedness \\
Ranking & gress with other players & \\
Tist of participants to missions and courses & This functionality is included to deal with the Relatedness intrinsic \\
& motivator with a view to stimulating user engagement by comparing and \\
& sharing the one's activities with friends and other players & Relatedness
\end{tabular}


Fig. 3 A mission card as it appears without the gamification elements

\section{Back Available missions}

Inspect the state of the streets in Leganés

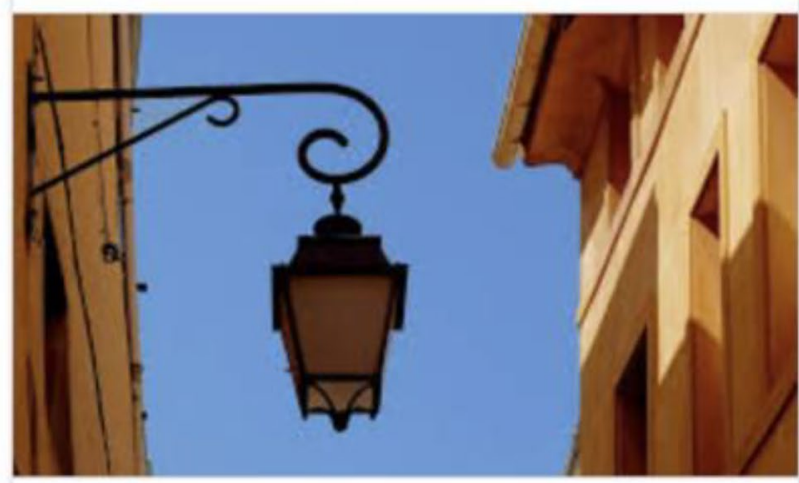

Inspect the condition of street furniture in The area assigned in the mission

\section{State: open}

Location: Leganés/Villaverde

Accept the mission

Inspect the state of the streets in Getafe

Table 2 The available missions

\begin{tabular}{ll}
\hline Name of the mission & Description \\
\hline District exploration & $\begin{array}{c}\text { It asks citizens to explore their neighborhood and collect photos of possible dangerous situ- } \\
\text { ations such as unstable trees after a storm } \\
\text { This mission asks citizens to monitor specific infrastructures or spaces to look for potential } \\
\text { problems such as the status of manholes, sidewalks or lamppost painting } \\
\text { It asks to check the status of the cleanliness in the area assigned in the mission (see Fig. 1b) }\end{array}$ \\
Decorous streets &
\end{tabular}

attention. In this work, we kept the original labels of the items and scales to maintain consistency with the work of O'Brien and Toms.

More specifically, the Perceived Usability (PU) items are related to the perception of the usability of users during the use of the artifact. The items of Felt involvement (FI) are related to the feeling of users of being drawn in, interested, and having fun during the interaction. The items of Aesthetics (AE) and Focused Attention (FA) refer to the visual perception of the artifact and the level of mental concentration during the activity.

Moreover, in the original O'Brien and Toms' work, two further categories were blended in the previous ones through the Principal Axis Factor analysis. They are 
Table 3 Engagement questionnaire

\begin{tabular}{|c|c|}
\hline Item & question \\
\hline \multicolumn{2}{|c|}{ Perceived usability } \\
\hline PU1 & I felt discouraged while using iWarn \\
\hline PU2 & I felt frustrated while using iWarn \\
\hline PU3 & I felt annoyed with using iWarn \\
\hline EN1 & My experience did not work out the way I had planned \\
\hline PU4 & I could not do some of the things I needed to do using iWarn \\
\hline PU5 & I found iWarn confusing to use \\
\hline PU6 & Using iWarn was mentally taxing \\
\hline PU7 & The mission experience was demanding \\
\hline PU8 & I felt in control of the mission experience \\
\hline \multicolumn{2}{|c|}{ Felt involvement } \\
\hline NO1 & I felt interested during my mission tasks \\
\hline $\mathrm{NO} 2$ & The content of iWarn incited my curiosity \\
\hline FI1 & My mission experience was fun \\
\hline FI2 & I felt involved in the mission tasks \\
\hline EN2 & My mission experience was rewarding \\
\hline EN3 & I would recommend iWarn to my friends and family \\
\hline FI3 & I was really drawn into my mission tasks \\
\hline EN4 & I consider my mission experience a success \\
\hline EN5 & Using iWarn was worthwhile \\
\hline \multicolumn{2}{|c|}{ Aesthetics } \\
\hline AE1 & The screen layout of iWarn appealed to my visual senses \\
\hline AE2 & The iWarn interface is aesthetically appealing \\
\hline AE3 & The iWarn interface is attractive \\
\hline AE4 & I liked the graphics and images used by iWarn \\
\hline \multicolumn{2}{|c|}{ Focused attention } \\
\hline FA1 & I was so involved in my mission task that I lost track of time \\
\hline FA2 & The time I spent doing the mission just slipped away \\
\hline FA3 & I lost myself in the mission experience \\
\hline FA4 & I blocked out things around me when I was using iWarn \\
\hline FA5 & I was absorbed in my mission task \\
\hline
\end{tabular}

Table 4 Specific questions for group using the gamified app

\begin{tabular}{ll}
\hline Item & question \\
\hline G1 & Receiving "points" for completing missions motivates me to use iWarn more than I would have otherwise \\
G2 & Seeing my progress through my "Rank" motivates me to play the App more than I would have otherwise \\
G3 & Comparing my progress in the "ranking" page with players of my city motivates me to use the App more \\
than I would have otherwise \\
G4 \\
K5owing who is participating in a "mission" motivates me to play the same mission \\
To be able to access more difficult "missions" according to my level motivates me to use the App more \\
than I would have otherwise
\end{tabular}

Novelty (NO) and Endurability (EN). The NO items are related to the level of interest of the user during the task and his curiosity evoked by the artifact. The EN items relate to the probability of reusing the system and the perception of its usefulness. Table 3 lists the items divided into 4 scales.
Moreover, we added some extra items to the Gr1's questionnaire to explore the effects of the gamification elements (Table 4). From now on we refer to the questionnaire of Gr1 as $G$ questionnaire and for Gr2 as $N G$ questionnaire.

Questions were answered using a 5-point Likert scale with 1 for strongly disagree, 5 for strongly agree and 3 for 
Table 5 Perceived usability

\begin{tabular}{llllllllll}
\hline & \multicolumn{1}{l}{ Perceived usability } & & & & & \\
\cline { 2 - 9 } & PU1 & PU2 & PU3 & EN1 & PU4 & PU5 & PU6 & PU7 & PU8 \\
\hline Gr1 mean & 3.8 & 3.8 & 3.8 & 4.0 & 3.8 & 3.4 & 4.6 & 3.6 & 4.1 \\
Gr2 mean & 3.5 & 3.1 & 3.4 & 3.0 & 3.3 & 3.3 & 4.8 & 4.4 & 3.0 \\
Difference & 0.3 & 0.7 & 0.4 & 1.0 & 0.5 & 0.1 & -0.2 & -0.8 & 1.1 \\
Gr1 S.D & 1.3 & 1.6 & 1.4 & 1.1 & 1.2 & 1.5 & 1.0 & 1.2 & 1.2 \\
Gr2 S.D & 1.2 & 1.4 & 1.3 & 1.1 & 1.2 & 1.5 & 0.4 & 1.0 & 1.2 \\
\hline
\end{tabular}

Table 6 Felt involvement

\begin{tabular}{llllllllll}
\hline & \multicolumn{2}{l}{ Felt involvement } \\
\cline { 2 - 9 } & NO1 & NO2 & FI1 & FI2 & EN2 & EN3 & FI3 & EN4 & EN5 \\
\hline Gr1 mean & 4.3 & 4.5 & 3.9 & 3.8 & 3.5 & 4.1 & 4.1 & 3.9 & 4.1 \\
Gr2 mean & 3.4 & 2.5 & 2.9 & 3.6 & 3.0 & 3.1 & 3.0 & 3.3 & 3.2 \\
Difference & 0.9 & 2.0 & 1.0 & 0.2 & 0.5 & 1.0 & 1.1 & 0.6 & 0.9 \\
Gr1 S.D & 0.8 & 0.8 & 1.4 & 1.1 & 1.4 & 1.1 & 0.9 & 1.4 & 1.2 \\
Gr2 S.D & 1.3 & 1.4 & 1.5 & 1.3 & 1.2 & 1.3 & 1.2 & 1.2 & 0.9 \\
\hline
\end{tabular}

Table 7 Aesthetics

\begin{tabular}{lllll}
\hline & \multicolumn{3}{l}{ Aesthetics } & \\
\cline { 2 - 5 } & AE1 & AE2 & AE3 & AE4 \\
\hline Gr1 mean & 4.1 & 4.0 & 4.2 & 4.5 \\
Gr2 mean & 2.7 & 2.9 & 2.9 & 3.1 \\
Difference & 1.4 & 1.1 & 1.3 & 1.4 \\
Gr1 S.D & 0.7 & 1.2 & 1.3 & 0.8 \\
Gr2 S.D & 1.2 & 1.2 & 1.2 & 1.2 \\
\hline
\end{tabular}

a neutral response. According to the literature, a 5-point Likert scale increases the response rate and quality and it also reduces respondents' "frustration level" (Buttle 1996; Babakus and Glynn Mangold 1992).

Finally, in order to complement the engagement questionnaire results, we also measured the NoL, AM and UP variables using the system logs collected during the week. The more the participants are engaged, the larger these variables are expected to be. Then, these can be used to measure in a quantitative fashion the efficacy of the motivation on the two different groups of participants.

\subsection{Tasks execution}

The 20 participants were asked to use the application for a whole week. Every day a new mission near each participant's location was published. Participants could apply to a mission at any moment of the week at their own pace. An email was sent to notify each participant every time a new mission was available and another email to the specific user every time (s)he accomplished a mission.
Table 8 Focused Attention

\begin{tabular}{llllll}
\hline & \multicolumn{2}{l}{ Focused Attention } & & \\
\cline { 2 - 6 } & FA1 & FA2 & FA3 & FA4 & FA5 \\
\hline Gr1 mean & 3.9 & 3.7 & 3.3 & 3.6 & 3.8 \\
Gr2 mean & 2.3 & 2.1 & 1.6 & 2.0 & 2.2 \\
Difference & 1.6 & 1.6 & 1.7 & 1.6 & 1.6 \\
Gr1 S.D & 0.5 & 0.6 & 0.5 & 0.7 & 0.6 \\
Gr2 S.D & 1.3 & 1.4 & 0.7 & 1.1 & 1.1 \\
\hline
\end{tabular}

Table 9 G questionnaire's additional items

\begin{tabular}{llllll}
\hline & \multicolumn{2}{l}{ Gamification } \\
\cline { 2 - 6 } & G1 & G2 & G3 & G4 & G5 \\
\hline Gr1 mean & 3.7 & 3.7 & 4.0 & 3.9 & 4.3 \\
Gr1 S.D & 1.3 & 1.1 & 0.8 & 0.7 & 0.7 \\
\hline
\end{tabular}

\subsection{Results and first considerations}

After a week of use, participants filled out the questionnaire to evaluate the perception of their engagement while using the system. All the participants answered all the questions. Tables 5, 6, 7, 8 describe and compare the means, the standard deviation of the items referred to the two different groups. Table 9 describes the data for the additional items related only to the gamified system.

Before analyzing the questionnaire results, we reversed the score of the negative items. As reported in the next tables, the standard deviation for each item is relatively low and in general participants of Gr1 were satisfied with their experience while $\mathrm{Gr} 2$ have slightly lower results. Indeed, all 
the differences are favorable to Gr1 apart from the PU6 and PU7 items described in Table 5. These two items are related to the user's cognitive load. that might be higher in the gamified version since the interface is more complex.

Concerning Felt Involvement, Gr1 scores better than Gr2 (see Table 6). In particular, NO2 is related to curiosity and FI3 related with the sense of involvement are significantly better rated in the gamified version.

In Tables 7 and 8, it is evident how the experience in the gamified version rates significantly higher in the Aesthetics and Focused attention scales. On the one side, the gamification elements seem to make the interface more pleasant and enjoyable, as was noticed also in (Stanculescu et al, 2016). Furthermore, the gamification mechanisms seem to make users pay closer attention to the application goals.

The results, presented in Table 8 , are especially significant because, as reported in the artefact section, there is no difference between the interfaces of the missions in the two versions of the application. This can be explained by the high results obtained in the additional items for the $G$ questionnaire (Table 9). These items are aimed at evaluating the user's motivation under the specific gamified elements of the platform.

All the items' scores are close or bigger than 4 that reveals a strong motivation due to the gamified logic of the application. This is especially evident in the G3, G4 and G5 items, whose means are respectively $4,3.9$ and 4.3. They show that users feel more motivated if they can relate to or compete with other users and can access progressively more complex missions.

After the questionnaire, users had the possibility to add some comments regarding their experience. Mainly the comments come from Gr1 and just a few from Gr2. Comments from $\mathrm{Gr} 1$ are in general positive and constructive. Regarding the utility of the application a user wrote: "The application is quite good because it invites and encourages people to participate and collaborate to the wellness of their community" or "For the wellness of my community I would feel compelled to play a certain mission if I knew that nobody is participating" and "Knowing if someone that I know is involved in a mission could stimulate me to do the same". About the competitiveness mechanism of the app, one said: "Seeing the ranking and comparing myself with the other players I think it encouraged me to perform the tasks" or "If I did not have a little bit of "healthy" competition, probably I would have done the missions just in case I were near the mission's location". Still, on the competitiveness aspect, one user said: "I would like to have a ranking divided in "leagues" with several categories of users based on the experience of each one" and "I think I would be more motivated if I received more points to accept more quickly a mission".

Regarding the daily usage one wrote: "I have not noticed any additional effort to my life to carry out the tasks that I
Table 10 Presents the log variables results, properly number of logins (NoL), number of uploaded pictures (UP), and number of accomplished missions (AM)

\begin{tabular}{llll}
\hline System logs & AM & NoL & UP \\
\hline GApp & 61 & 158 & 194 \\
NgApp & 42 & 103 & 115 \\
\hline
\end{tabular}

have been asked during the week", while another highlighted the desire to have a more playful experience: "The daily challenge could be different / have more variety so it will be more challenging". About the gamification experience, one said: "I'd prefer to receive the points as soon as I complete the mission, would be more rewarding". This is because at the moment the system assigns points just after an operator checks the photos sent in the mission. Finally, regarding the photos collected during a mission we received some other considerations: "One thing that I missed in the application is to be able to add a comment about the photo that I send" and "I would like to put a symbol of thumb up or thumb down to say if there is a problem or not in the picture I took".

From the Gr2 we got just a few comments regarding the appeal of the missions: "Missions should be more appealing and in general you should improve the user experience of the app". "It could be very interesting and engaging to me if the missions were more varying and appealing but after the first ones my interest diminished". As we said before, an important consideration is that both the kinds of missions and the mission interface are exactly the same for both groups, then the gamification mechanisms seem to make more pleasant end interesting also the mission experience.

The difference in the number of the comments between the two groups and the constructive tone used by users in Gr1 suggest a different level of engagement and reflect the questionnaire indications that a better perception of the gamified app with respect to the non-gamified one.

Similar conclusions are given by the analysis of the system logs obtained during the experiment. Table 10 describes the means of the number of accomplished missions, logins and uploaded pictures. Also, in this case, the numbers are all in favor of the first group. There are 61 missions accomplished in the gamified system against 42 in the other version; 158 logins against 103 and 194 pictures uploaded in 1 week using the GApp against the 115 uploaded using the second app.

Figures 4 and 5 show the percentage of the accomplished missions per user. It is evident the difference between the two groups. In particular, the minimum percentage for Gr1 is 71,4 while for Gr2 is only 28,5 . Even if each user was asked to play a mission for each day, some users played more: in Gr1 3 users played one more mission while in Gr2 just 1 user did.

Therefore, we can give our first considerations by stating that the gamification component positively affects the civic 
Fig. 4 Percentage of accomplished missions per user in team Gr1
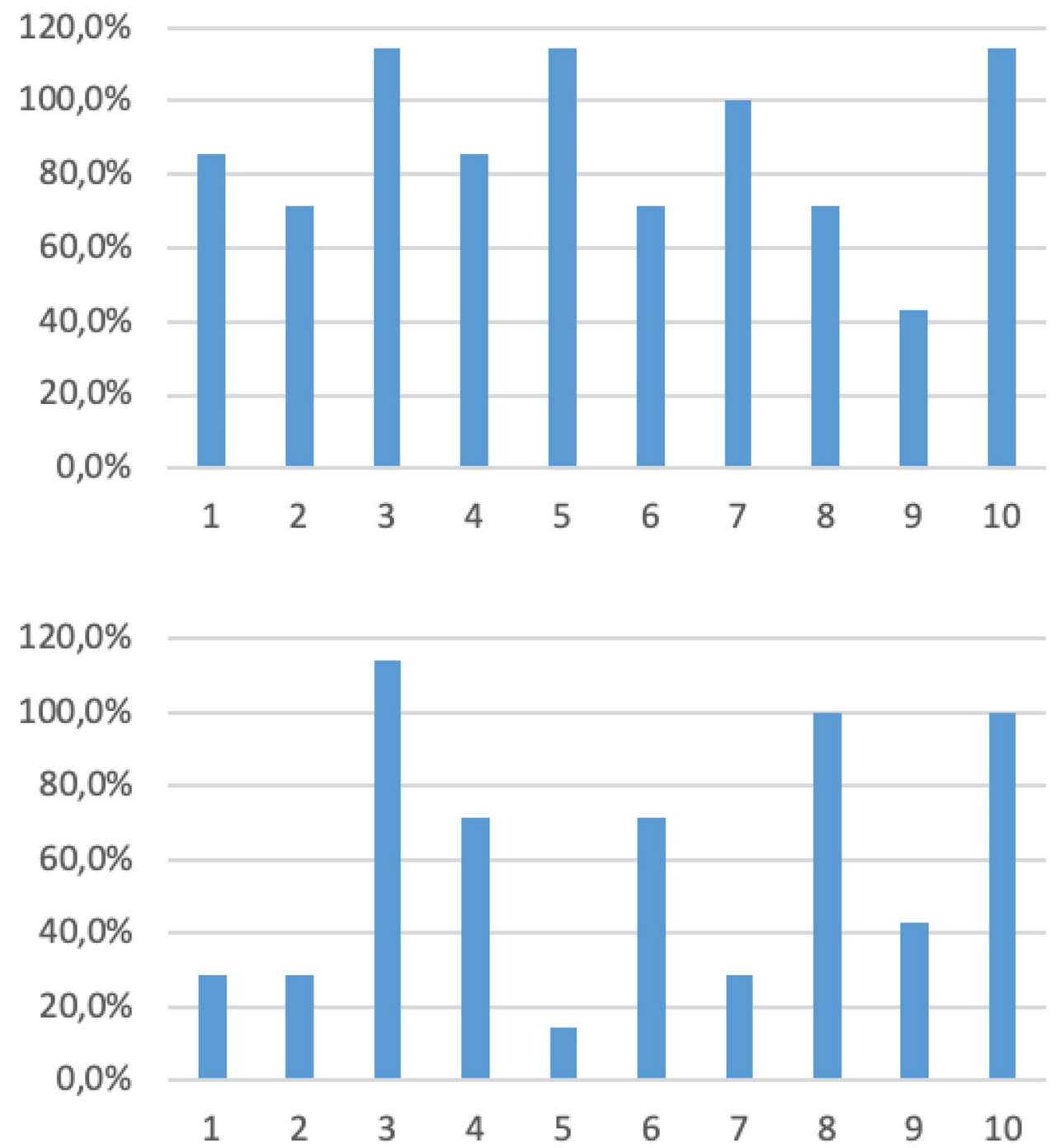

Fig. 5 percentage of accomplished missions per user in team Gr2 participation and makes the use of the system more effective. In the following section, we perform a statistical analysis to prove our first considerations.

\subsection{Hypothesis verification: parametric and nonparametric tests}

In order to prove that the results were not casually derived, we have applied the nonparametric test of Mann-Whitney (Mann and Whitney 1947) to compare the questionnaire items' means and see if the null hypothesis, specifically there is no difference between the two means of the same item, is rejected. Such a test is appropriate when one needs to test differences between two conditions and different participants, and it is appropriate to compare Likert scale means (Field 2013). In this test, if the $\operatorname{Sig}$ (2-tailed) p-value is less than 0.05 then the two groups are significantly different. In our case, the two conditions are represented by the independent variable of the artifact: GApp and NgApp.
Table 11 Cronbach's alpha

\begin{tabular}{llll}
\hline Scale & N. of items & Alpha G & Alpha NG \\
\hline PU & 9 &, 9 &, 8 \\
FI & 9 &, 9 &, 9 \\
AE & 4 &, 9 &, 9 \\
FA & 5 &, 7 &, 8 \\
Gam & 5 &, 9 & $/$ \\
\hline
\end{tabular}

In (Hertzog 2008), the author stated that it is recommendable to run a reliability analysis to validate small studies with size samples under 25. For such reason, we ran the reliability analysis test based on the Cronbach's Alpha coefficient (Cronbach 1951) using the IBM SPSS Statistics software. ${ }^{5}$ The coefficient must be calculated for each questionnaire

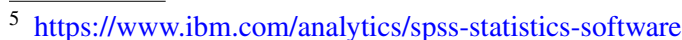


Table 12 recapping the results

\begin{tabular}{lll}
\hline STD motivator & The sentiments generated by the motivators & Sources \\
\hline Relatedness & (a) Spirit of competition & Questionnaire items: G2, G3, G4 \\
& (b) Sense of belonging together & Collected comments \\
Competence & (c) Self-confidence & Questionnaire items: G1, G5 \\
& (d) Desire to face more difficult challenges & Collected comments \\
Autonomy & (e) Curiosity & Questionnaire items: FA1-5, \\
& (f) Enjoyment & AE1, AE3, AE4, NO2, FI3, G5 \\
& (g) Feeling absorbed in the task & Collected comments \\
& (h) Social commitment & Logs item: UP \\
\hline
\end{tabular}

scale (Field 2013) and its value should be close to 0.8 (Hertzog 2008).

Table 11 describes the results of the reliability analysis test. All the Cronbach's Alpha coefficients are above or close to 0.8 . Only the FA scale constant (0.7) for the $G$ questionnaire is lower than the desired thresholds. Even if this is not a bad result, the reliability analysis run with the SPSS software showed that we may improve the reliability of this scale to the 0.8 thresholds by removing the item FA2 and rerunning the analysis. FA2 is related to the perception of the passing of time during the task. Then, further investigation in this dimension might be required in the future.

However, we can argue that the results of our questionnaires are reliable and that can be used in our analysis.

Regarding the items' comparison, in the Perceived usability scale there are no p-values less than 0.05. So, the null hypothesis cannot be rejected for all of them. This means that gamification does not really affect the perception of usability as preliminary results could suggest. Regarding the felt involvement, two items present a p-value significantly small, those are No2 $(0,003)$ and FI3 $(0,047)$. NO2 regards the curiosity stimulated by the content of iWarn and FI3 related to the sense of involvement. Therefore, they are still interesting items as commented before and this demonstrates that gamification positively affects the Felt involvement scale by increasing curiosity and the sense of involvement in the mission tasks. Finally, the nonparametric test reveals that the gamification used in our prototype positively affects almost the whole Aesthetics scale, properly AE1, AE3, AE4 has a $\mathrm{p}$ value respectively of $0.009,0.027,0.008$, and the whole Focused attention scale, respectively in order 0.006, 0.007, $0.000087,0.003,0.003$. This confirms the preliminary considerations commented in the previous section.

Finally, in order to prove that considerations on the log variables, properly number of logins (NoL), number of uploaded pictures (UP) and number of accomplished missions (AM), we applied a two-tailed t-test with a $\mathrm{p}$ value $<0.005$ on the collected system logs for each pair of groups we want to compare. Before performing the test, we analyzed the distribution of the means in order to find possible outliers that could affect the test. No outliers were found using SPSS.
Then, we formulated three null hypotheses:

- H0 (null hypothesis): the number of the accomplished missions by $\mathrm{Gr} 1$ and $\mathrm{Gr} 2$ is the same

- H1 (null hypothesis): the number of accesses to the system by Gr1 and Gr2 is the same

- H2 (null hypothesis): the number of uploaded photos during the missions by $\mathrm{Gr} 1$ and $\mathrm{Gr} 2$ is the same

The resulted p-values for AM, NoL and UP are respectively $0.63,0,088$ and 0,033 . The only p-value enough small to reject a null hypothesis is the one of UP. In other words, just $\mathrm{H} 2$ is rejected while there is no significant difference between the number of missions accomplished and accesses during the experiment week. This can be explained by the fact that all the users knew to have 1 week to participate and perform the experiment, but evidently, the members of $\mathrm{Gr} 1$ were more motivated and took more photos. Based on this result, we can conclude that in our experiment, the gamification approach can have considerably and positively and not accidental effects on civic participation.

\section{Discussion}

In this section we discuss the results presented above mapping them onto the three intrinsic motivators of the SDT and highlighting the sentiments generated by each of the motivators.

The collected comments and the questionnaire items dedicated to the gamified app show that the app mechanism is able to activate the intrinsic motivator of Relatedness generating (a) Spirit of competition (b) Sense of belonging together. Indeed, is evident that the users appreciate the possibility to see their progress, to compare them with users of the same city, to know who is playing in the mission and to feel to belong to the same community. Moreover, they also show some behaviors related to the Competence motivator. During the usage of the application, the users are able to recognize the improvement of their skills and look for more missions to play and more advanced challenges. These generate the sentiments of (c) Self-confidence (d) Desire to 
face more difficult challenges. Finally, the comparison of the system logs and questionnaire items common for the two groups show the activation of the Autonomy motivator. Indeed, Gr1's users appreciate the application interface and enjoy playing with it. They feel to be both more absorbed into the missions and more motivated to take photos than the other group. Definitely, they reveal a positive commitment to the social objectives proposed by the application, which is exactly in line with the principles of Autonomy. Then, it generates (e) Curiosity, (f) Enjoyment (g) Felting absorbed in the task, and (h) Social commitment. Table 12 recaps the main results mapping them onto the three intrinsic motivators and the corresponding sources.

As stated by Malone in (Malone 1981) the main reason to use gamification is to rise motivation. The experiment presented in this work shows that gamification applied in the context of civic participation is effective to rise it through intrinsic motivators. Moreover, as explained in (Hassan 2017), there is still a lack of knowledge regarding gamification in civic participation. The comparative experiment presented here helps to fill the void by identifying which aspects of the user experience and engagement are mostly affected by the gamification in this given context and showing which SDT motivators are activated and how they influence the user behavior and sentiments. It also answers the research question: "May a gamified system foster civic participation better than a non-gamified one?". Indeed, our gamified app demonstrated to better promote positive and participative behaviors towards the objective of the application. The experiment design is based on the designs presented in (Thom et al. 2012; Stanculescu et al. 2016) where gamification effects are measured by removing gamification features from a system and perform a comparative study. The main difference is the context: in the aforementioned experiments users are workers of an enterprise so they use the provided software with more or less motivation that can be affected by gamification. In the civic participation context, the application proposed in the experiment requires that users perform actions in the wild that could be out of their comfort zone, then the adoption and the usage of a similar tool cannot be taken for granted (Delli Carpini 2000) and the motivation techniques can play an important role to persuade citizens as demonstrated in this experiment.

In any case, the study here presented is limited in its scope, since it was applied just for 1 week in a specific city and involving a small number of participants. The combination of cultural and urban settings is almost infinite so that generalizing results is not always possible. Moreover, the experiment only explored the intrinsic motivators and did not explore the possible effects of extrinsic motivators such as physical prizes and rewards. Anyway, the initial findings suggest that further research on how to raise civic participation can take advantage of the common game mechanisms.

\section{Conclusions and final remarks}

In this work, we investigated the research question "May a gamified system foster civic participation better than a nongamified one?". To do so, we here presented a comparative study of the effects on the civic participation of a gamified app and its non-gamified version. Both versions provide users with civic missions to prevent emergency situations or to reveal city problems. The experiment has lasted one whole week, during this time 20 participants have used one of the two versions of the app and have received tasks to accomplish near the place they live. The results of the study revealed that the gamification mechanisms positively affect civic engagement and the efficacy of the application. All the gamification elements were positively evaluated by the users and in particular, they appreciated the possibility to interact and compete with other users, and the possibility to progress and access more difficult missions.

We can summarize the results as follow: (a) the gamification makes users feel more curious and involved in the social objectives of the application, (b) it improves the joy of using the app (c) it significantly enhances the attention and commitment while users act in a mission.

Notwithstanding the good results, the experiment lasted just for 1 week, then we still need to experiment with the effects of the gamification on the engagement in the medium to long-term. Therefore, we plan to run a new iteration of the study with a significantly larger group of participants after concluding agreements with some emergency organizations or local governments to experiment with the system in the real life with real problems. This will allow us to confirm or discard the preliminary results obtained so far and make definitive conclusions on the usage of gamification in civic participation.

Funding Open access funding provided by Università degli Studi di Salerno within the CRUI-CARE Agreement. The research is partially supported by Ministerio de Asuntos Económicos y Transformación Digital (MINECO), Award number: TIN2016-77690-R and by the Italian Ministry Universities and Research MUR 2019 Grant number: AIM1872991-2.

Availability of data and material The raw data that support the findings of this study are available on request from the corresponding author, MR. The data are not publicly available because containing some information that could compromise the privacy of research participants.

Code availability Application code is not publicly released. Anyway, it is possible to send a motivated request the corresponding author, MR.

\section{Declarations}

Conflict of interest The authors declare no conflicts of interest. 
Open Access This article is licensed under a Creative Commons Attribution 4.0 International License, which permits use, sharing, adaptation, distribution and reproduction in any medium or format, as long as you give appropriate credit to the original author(s) and the source, provide a link to the Creative Commons licence, and indicate if changes were made. The images or other third party material in this article are included in the article's Creative Commons licence, unless indicated otherwise in a credit line to the material. If material is not included in the article's Creative Commons licence and your intended use is not permitted by statutory regulation or exceeds the permitted use, you will need to obtain permission directly from the copyright holder. To view a copy of this licence, visit http://creativecommons.org/licenses/by/4.0/.

\section{References}

Ampatzidou C, Constantinescu T, Berger M, Jauschneg M, Gugerell K, Devisch O (2018) All work and no play? Facilitating serious games and gamified applications in participatory urban planning and governance. Urban Planning 3(1):34-46

Apostolopoulos K, Geli M, Petrelli P, Potsiou C, Ioannidis C (2018) A new model for cadastral surveying using crowdsourcing. Surv Rev 50(359):122-133

Babakus E, Mangold WG (1992) Adapting the SERVQUAL scale to hospital services: an empirical investigation. Health Serv Res 26(6):767

Botte B, Bakkes S, Veltkamp R (2020) Motivation in gamification: constructing a correlation between gamification achievements and self-determination theory. International conference on games and learning alliance. Springer, Cham, pp 157-166

Buttle F (ed) (1996) Relationship marketing: theory and practice. Sage, London

Coe A, Paquet G, Roy J (2001) E-governance and smart communities: a social learning challenge. Soc Sci Comput Rev 19(1):80-93

Coronado Escobar JE, Vasquez Urriago AR (2014) Gamification: an effective mechanism to promote civic engagement and generate trust? In: Proceedings of the 8th International Conference on Theory and Practice of Electronic Governance, pp 514-515

Cronbach LJ (1951) Coefficient alpha and the internal structure of tests. Psychometrika 16(3):297-334

DelliCarpini MX (2000) Gen. com: Youth, civic engagement, and the new information environment. Polit Commun 17(4):341-349

Deterding S, Dixon D, Khaled R, Nacke L (2011) From game design elements to gamefulness: defining "gamification". In: Proceedings of the 15th International Academic MindTrek Conference: Envisioning Future Media Environments, pp 9-15

Díaz P, Carroll JM, Aedo I (2016) Coproduction as an Approach to Technology-Mediated Citizen Participation in Emergency Management. Future Internet 8(3):41

Díaz P, Onorati T, Aedo I (2017) A digital knowledge ecosystem to increase participation in emergency warnings and alerts management. Green, pervasive, and cloud computing. Springer, Cham, pp 700-711

Field A (2013) Discovering statistics using IBM SPSS statistics. Sage, New Jersey

Hassan L (2017) Governments should play games: towards a framework for the gamification of civic engagement platforms. Simul Gaming 48(2):249-267

Hassan L, Hamari J (2020) Gameful civic engagement: A review of the literature on gamification of e-participation. Gov Inf Q 37(3): 101461

Hassan L, Thibault M (2020) Critical playable cities. Making smart cities more playable. Springer, Singapore, pp 71-85
Hertzog MA (2008) Considerations in determining sample size for pilot studies. Res Nurs Health 31(2):180-191

Jennings J (2004) Urban planning, community participation, and the Roxbury Master Plan in Boston. Ann Am Acad Pol Soc Sci 594(1):12-33

Kanat IE, Siloju S, Raghu TS, Vinze AS (2013) Gamification of emergency response training: a public health example. In: 2013 IEEE International Conference on Intelligence and Security Informatics, IEEE, pp 134-136

Kapp K, Lucas B, Mesch R (2012) The gamification of learning and instruction: game-based methods and strategies for training and education. John Wiley \& Sons, New Jersey

Karra S, Karampa V, Paraskeva F (2019) Gamification design framework based on self determination theory for adult motivation. International workshop on learning technology for education in cloud. Springer, Cham, pp 67-78

Kazhamiakin R, Marconi A, Martinelli A, Pistore M, Valetto G (2016) A gamification framework for the long-term engagement of smart citizens. In: 2016 IEEE International Smart Cities Conference (ISC2), IEEE, pp 1-7

Koivisto J, Hamari J (2019) The rise of motivational information systems: a review of gamification research. Int J Inf Manag 45:191-210

Landers RN, Auer EM, Collmus AB, Armstrong MB (2018) Gamification science, its history and future: definitions and a research agenda. Simul Gaming 49(3):315-337

Magnette P (2003) Contrôler l'Europe: pouvoir et responsabilités dans l'Union européenne. Editions de l'Université de Bruxelles

Mainka A, Castelnovo W, Miettinen V, Bech-Petersen S, Hartmann S, Stock WG (2016) Open innovation in smart cities: civic participation and co-creation of public services. Proc Assoc Inf Sci Technol 53(1):1-5

Makri E, Spiliotopoulos D, Vassilakis C, Margaris D (2020) Human behaviour in multimodal interaction: main effects of civic action and interpersonal and problem-solving skills. J Ambient Intell Human Comput 11(12):5991-6006

Malone TW (1981) Toward a theory of intrinsically motivating instruction. Cogn Sci 5(4):333-369

Mann HB, Whitney DR (1947) On a test of whether one of two random variables is stochastically larger than the other. Ann Math Stat 18:50-60

McCallum S (2012) Gamification and serious games for personalized health. In: pHealth, pp 85-96

Mylonas G, Paganelli F, Cuffaro G, Nesi I, Karantzis D (2021) Using gamification and IoT-based educational tools towards energy savings-some experiences from two schools in Italy and Greece. J Ambient Intell Humaniz Comput. https://doi.org/10.1007/ s12652-020-02838-7

O'brien HL, Toms EG (2013) Examining the generalizability of the User Engagement Scale (UES) in exploratory search. Inf Process Manag 49(5):1092-1107

Pelling N (2011) The (short) prehistory of gamification. Funding startups (\& other impossibilities). Haettu 7:2013

Ramadan Z (2018) The gamification of trust: the case of China's "social credit." Marketing Intell Plan 36:93-107

Rodrigues M, Monteiro V, Fernandes B, Silva F, Analide C, Santos R (2019) A gamification framework for getting residents closer to public institutions. J Ambient Intell Humaniz Comput 11:4569-4581

Romano M, Díaz P, Aedo I (2016a) Emergency management and smart cities: civic engagement through gamification. International conference on information systems for crisis response and management in mediterranean countries. Springer, Cham, pp 3-14 
Romano M, Onorati T, Aedo I, Díaz P (2016b) Designing mobile applications for emergency response: citizens acting as human sensors. Sensors 16(3):406

Romano M, Díaz P, Aedo I (2018) A gamified platform for civic engagement in early warning. In: Proceedings of the XIX International Conference on Human Computer Interaction, ACM, p 2

Ryan RM, Deci EL (2000) Self-determination theory and the facilitation of intrinsic motivation, social development, and well-being. Am Psychol 55(1):68

Seaborn K, Fels DI (2015) Gamification in theory and action: A survey. Int J Hum Comput Stud 74:14-31

Sgueo G (2019) Is gamification making cities smarter? Ius Publicum Network Review. https://ssrn.com/abstract $=3315373$

Simões J, Redondo RD, Vilas AF (2013) A social gamification framework for a K-6 learning platform. Comput Hum Behav 29(2):345-353

Stanculescu LC, Bozzon A, Sips RJ, Houben GJ (2016) Work and play: An experiment in enterprise gamification. In: Proceedings of the 19th ACM Conference on Computer-Supported Cooperative Work and Social Computing, ACM, pp 346-358

Stembert N, Mulder I (2013) Love your city! An interactive platform empowering citizens to turn the public domain into a participatory domain. In: International conference using ICT, social media and mobile technologies to foster self-organisation in urban and neighbourhood governance, Delft, The Netherlands, 16-17 May 2013. http://resolver.tudelft.nl/uuid:23c4488b-09e14b90-85e3-143e4a144215

Thiel SK (2016) A review of introducing game elements to e-participation. In: 2016 Conference for E-Democracy and Open Government (CeDEM), IEEE, pp 3-9

Thom J, Millen D, DiMicco J (2012) Removing gamification from an enterprise SNS. In: Proceedings of the Acm 2012 Conference on Computer Supported Cooperative Work, ACM, pp 1067-1070

Toots M (2019) Why E-participation systems fail: the case of Estonia's Osale. ee. Gov Inf Q 36(3):546-559

Werbach K, Hunter D (2012) For the win: how game thinking can revolutionize your business. Wharton Digital Press, Boston (2012). ISBN 1613630239

Wilson P (1997) Smart communities guidebook. Developed by California Institute for Smart Communities at San Diego State University

Publisher's Note Springer Nature remains neutral with regard to jurisdictional claims in published maps and institutional affiliations. 